\title{
Bone lengthening osteogenesis, a combination of intramembranous and endochondral ossification: an experimental study in sheep
}

\author{
Francisco Forriol - Luca Denaro • \\ Umile Giuseppe Longo $\cdot$ Hirofumi Taira • \\ Nicola Maffulli $\cdot$ Vincenzo Denaro
}

Received: 6 July 2009/ Accepted: 18 February 2010/Published online: 10 March 2010

(C) Springer-Verlag 2010

\begin{abstract}
We evaluated the morphological features of the newly formed tissue in an experimental model of tibial callotasis lengthening on 24 lambs, aged from 2 to 3 months at the time of operation. A unilateral external fixator prototype Monotube Triax ${ }^{\circledR}$ (Stryker Howmedica Osteonics, New Jersey) was applied to the left tibia. A percutaneous osteotomy was performed in a minimally traumatic manner using a chisel. Lengthening was started 7 days after surgery and was continued to $30 \mathrm{~mm}$. The 24 animals were randomly divided into three groups of 8 animals each: in Group 1, lengthening took place at a rate of $1 \mathrm{~mm} /$ day for 30 days; in Group 2, at a rate of $2 \mathrm{~mm} /$ day for 15 days; in Group 3, at a rate of $3 \mathrm{~mm} /$ day for 10 days. In each group, 4 animals were killed 2 weeks after end of lengthening, and the other 4 animals at 4 weeks after end of lengthening. To assess bony formation in the distraction area, radiographs were taken every 2 weeks from the day of surgery. To study the process of vascularization, we
\end{abstract}

F. Forriol · H. Taira

Research Unit, FREMAP Hospital, Madrid, Spain

L. Denaro

Department of Neurosurgery,

Catholic University School of Medicine,

Rome, Italy

U. G. Longo · V. Denaro

Department of Orthopaedic and Trauma Surgery,

Campus Biomedico University, Via Alvaro del Portillo,

200, Trigoria, 00128 Rome, Italy

\section{N. Maffulli ( $\square)$}

Centre for Sports and Exercise Medicine,

Mile End Hospital, Barts and The London

School of Medicine and Dentistry, London, UK

e-mail: n.maffulli@qmul.ac.uk used Spalteholz's technique. After killing, the tibia of each animal was harvested, and sections were stained with hematoxylin and eosin, Masson's trichrome, and Safranin-O. Immunohistochemistry was performed, using specific antibodies to detect collagens I and II, S100 protein, and fibronectin. A combination of intramembranous and endochondral ossification occurred together at the site of distraction. Our study provides a detailed structural characterization of the newly formed tissue in an experimental model of tibial lengthening in sheep and may be useful for further investigations on callotasis.

Keywords Callotasis - Bone lengthening - Callus . Intramembranous ossification · Endochondral ossification

\section{Introduction}

Bone lengthening through callus distraction (callotasis) has widespread clinical application in the management of many orthopedic conditions [1-7]. While many of the technical difficulties have been addressed [8-10], the precise mechanism through which the formation of new bone occurs during callotasis is still debated [11-17], and a lack of consistency in the published literature remains on the histological findings at the site of formation of new bone [18-21]. Both endosteal and periosteal bone formation have been proposed to occur during distraction [22-25]. Endochondral ossification from the central fibrous tissue has been shown in the distraction gap in experimental models of distraction osteogenesis in rabbits [24, 26]. On the other hand, intramembranous ossification has been proposed to result when a low distraction rate under stable external fixation is applied [22, 23, 27-30]. A combination of both intramembranous and endochondral ossification 
within the same distraction callus has been found in other experimental investigations [31-34].

Mechanical and biological variables influence the lengthening processes, and many are not fully understood [35-40]. Moreover, the role played by vessels in the lengthened callus, the influence of the rigidity or dynamization of the fixator, and the forces which are transmitted through the external fixator during lengthening are still debated [12-16]. The effects of lengthening on the soft tissues and the articular and physeal cartilage likewise remain to be established, from both a clinical and an experimental point of view [38, 41].

Evaluation of the structural responses to osteotomy and subsequent distraction should help to understand the biological mechanism of distraction osteogenesis. We therefore undertook a study of tibial lengthening in sheep to evaluate (a) the type of ossification (intramembranous or endochondral) occurring at the site of callus distraction, (b) the pattern of vascularization of the regenerate bone during distraction osteogenesis, and (c) the immunohistochemical distribution of collagens type I and II, S-100 protein, and fibronectin.

\section{Materials and method}

We performed callotasis lengthening of the left tibia in 24 lambs aged from 2 to 3 months with an average weight of $18 \mathrm{~kg}$ at the time of operation. The study was approved by the Ethics Committee for Animal Research. Animal care was in accordance with our institutions Animal Laboratory Committee Guidelines and under the supervision of a veterinarian team.

Limb lengthening protocol

Intravenous atropine, tiobarbital, and fentanyl were given at induction at a dosage of $0.5,12$, and $0.0015 \mathrm{mg} / \mathrm{kg}$, respectively. General anesthesia consisted of intravenous tiobarbital $(10 \mathrm{mg} / \mathrm{kg})$ and fentanyl $(0.0015 \mathrm{mg} / \mathrm{kg})$.

We used the technique described by Noonan et al. [4]. A unilateral external fixator Monotube Triax $^{\circledR}$ (Stryker Howmedica Osteonics, New Jersey), especially designed for work with lambs (Jacquet Orthopedie, Stryker Trauma, Geneva), was fitted to the left tibia. This modified unilateral external fixator has four pins, two proximal and two distal in each of its pin holding clamps. A transverse percutaneous osteotomy of the midshaft of the tibia was performed in a minimally traumatic manner using a chisel [4]. After 7 days surgery, lengthening was started and lasted until each operated limb was lengthened by $30 \mathrm{~mm}$. The 24 animals were randomly divided into three groups of 8 animals each according to the distraction rates in the following manner:
Group 1: a rate of $1 \mathrm{~mm} /$ day for 30 days, Group 2: a rate of $2 \mathrm{~mm} /$ day for 15 days, Group 3: a rate of $3 \mathrm{~mm} /$ day for 10 days.

Distraction was performed once a day. In each group, four animals were killed at 2 weeks after the end of lengthening, and the other four were killed at 4 weeks after the end of lengthening.

Spalteholz's technique

To study the vascularization during distraction osteogenesis, we used Spaltefolz's technique [42, 43]. In brief, Berlin blue solution was injected through the femoral artery before killing. The animals were killed with an overdose of pentobarbital administered intravenously $(150 \mathrm{mg} / \mathrm{Kg}$ of body weight), and the operated tibia was excised in its entirety for analysis.

Radiographic study

To assess bony formation in the distraction area, radiographs were taken every 2 weeks from the day of surgery.

Histological studies

The harvested tibia was placed in $10 \%$ buffered formaldehyde. Using an oscillating saw, we cut the tibia longitudinally. The specimens were decalcified in EDTA for 2-3 weeks. After decalcification was confirmed radiographically, we proceeded to place them in paraffin and section them with a microtome into $4-\mu \mathrm{m}$ thick sections. The sites for histological evaluation were the proximal end of the regenerate (Level 1), the central area of the regenerate (Level 2), and the distal end of the regenerate (Level 3). Sections were stained with hematoxylin and eosin (H.E.), Masson's trichrome and Safranin-O and analyzed with a microscope with an image analysis system (Leica Q 500 MC, Cambridge, UK).

Immunohistochemical studies

Specific antibodies were used for immunohistochemical analysis. Deparaffinized sections were enzymatically pretreated, incubated with primary antibodies [anti-type I collagen (Biogenesis, 1/20), anti-type II collagen (Biogenesis, 1/20), anti-S100 protein (Sigma, 1/500), and anti-fibronectin (Sigma, 1/500)] overnight at $4^{\circ} \mathrm{C}$, and visualized using the avidin-biotin complex techniques. These antibodies show no cross-reactivity with any other targets. Nuclei were counterstained with hematoxylin, and the color reaction was produced with $0.03 \%$ 3.3-diaminobenzidine tetrachloride. As a negative control for immunohistochemical staining, the primary antibody was 


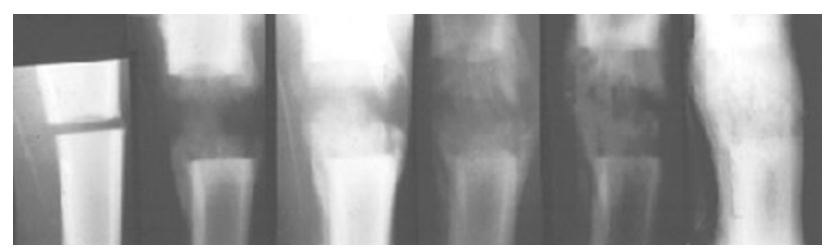

Fig. 1 Radiographic monitoring of the regenerate. The width of hypodense zone is constant. The regenerate has a striated appearance
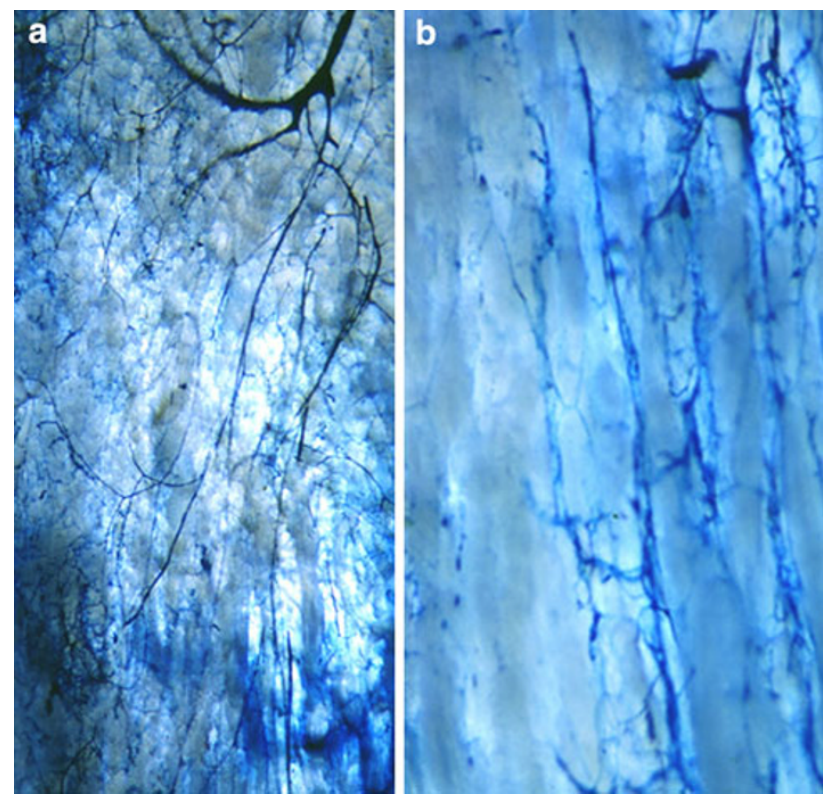

Fig. 2 Vascularization by Spalteholz's technique. Early repair of medullary artery after transverse osteotomy (a). Vascular anastomoses between periosteal and medullary vessels, which, penetrating the cortical bone, provide vascularisation to the regenerate (b) replaced by non-immuno mouse serum or Tris-buffered saline ( $\mathrm{pH} 7.36)$.

\section{Results}

All 24 lambs survived and showed good tolerance to the lengthening regimens used. The lambs experienced no postoperative complications and used the operated leg normally at daily exercise.

\section{Radiological evaluation}

Bone formation within the gradually widened gap was seen on the plain radiographs. During distraction, calcification started from both bone ends and progressed toward the central hypodense zone. The regenerate zone had a striated appearance. The hypodense interzone persisted for the whole duration of distraction and gradually diminished during consolidation phase. Bony fusion was observed 4 weeks after the end of distraction (Fig. 1).

\section{Evaluation of vascularization (Spalteholz's technique)}

The features of vascularization of the regenerate during distraction osteogenesis are shown in Fig. 2a, b. Prompt restoration of the continuity of the medullary artery was seen despite complete transverse osteotomy, and arterial branches from the medullary artery progressed into the regenerate (Fig. 2a). The vascular anastomoses between periosteal and endomedullary vessels, which penetrated the intracortical gap, were demonstrated by Spalteholz's
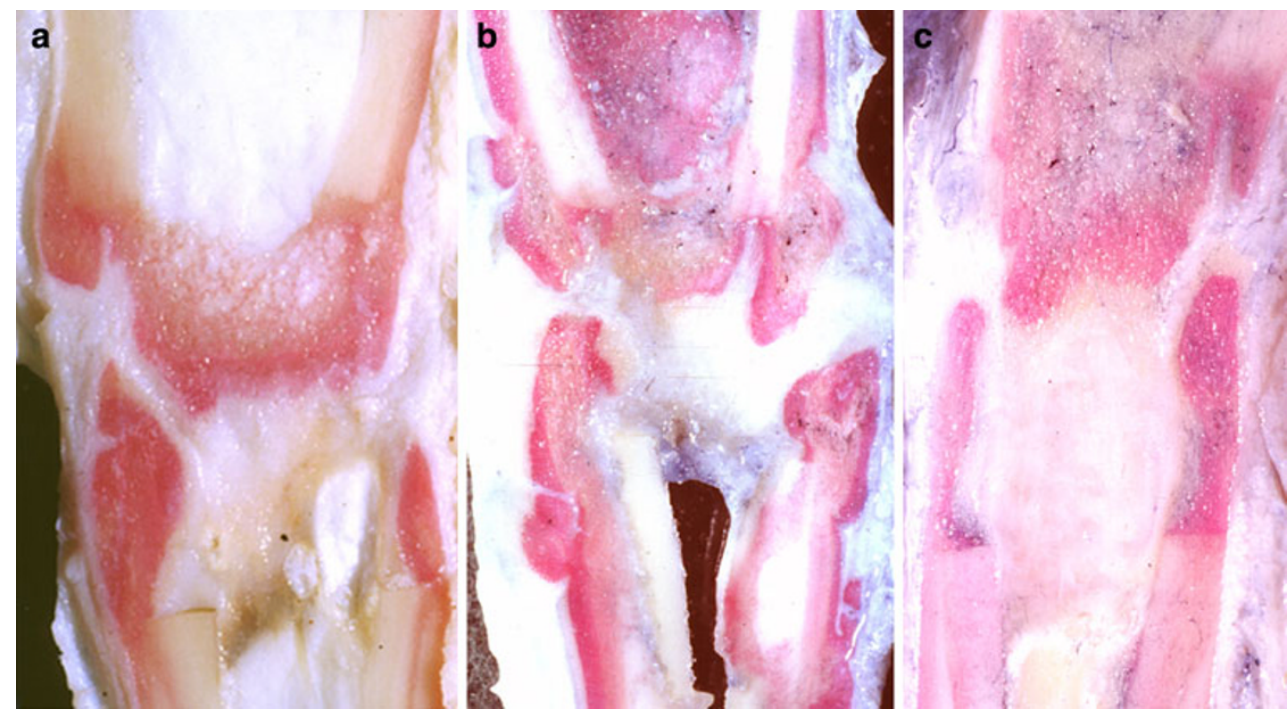

Fig. 3 Macroscopic appearance of the regenerate. The thickness of the fibrous tissue, formed between both ends of distracted bone fragments, was different according to the rates of distraction: a $1 \mathrm{~mm} /$ day; b $2 \mathrm{~mm} /$ day; c $3 \mathrm{~mm} /$ day 

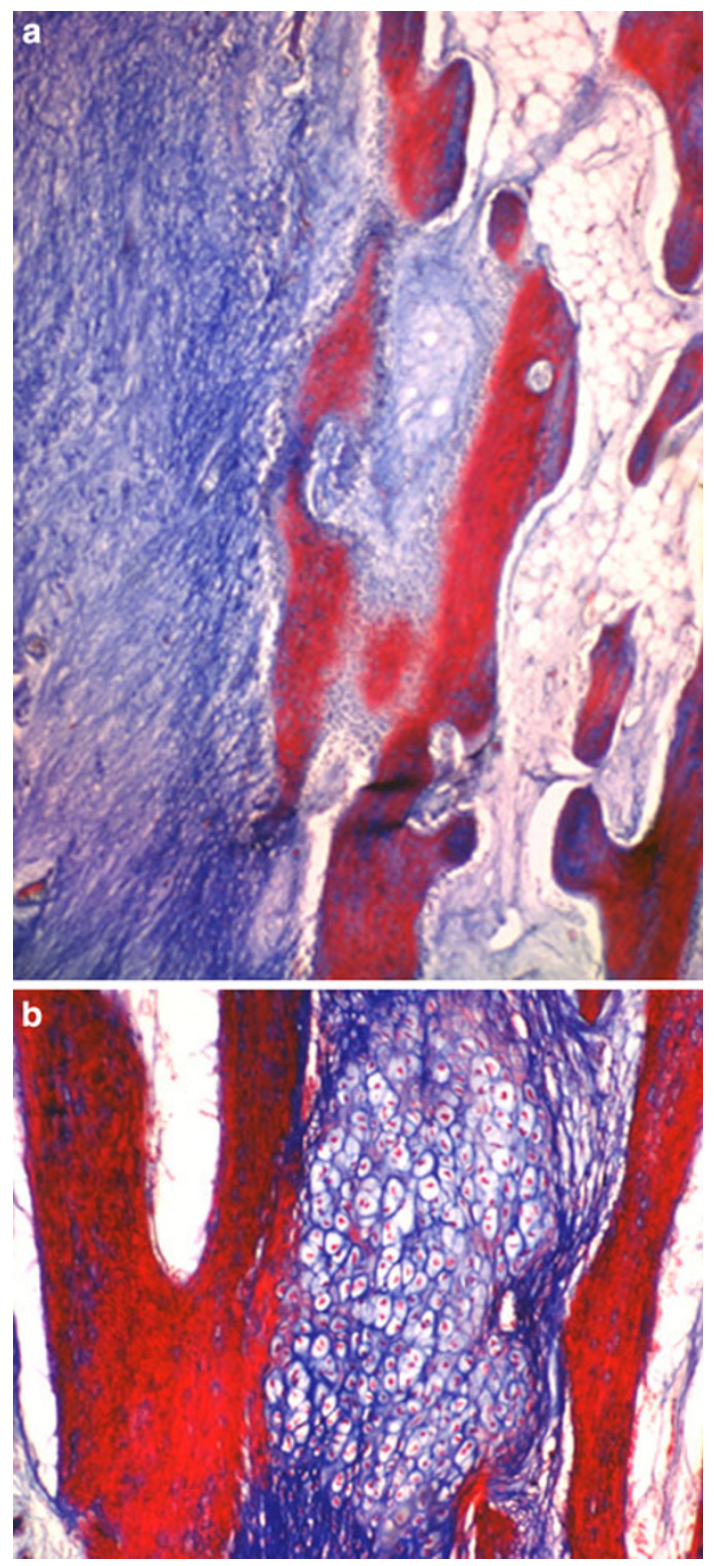

Fig. 4 a and b Microphotograph of intramembranous ossification. Osteoblasts on the surface of newly formed bone trabeculae surrounded by fibrous tissue from which the osteoblasts differentiated (Masson trichrome, $\times 100$ )

technique. The penetrating artery also provided branches toward the regenerate (Fig. 2b).

Histological evaluation

At macroscopic evaluation of longitudinal sections, the thickness of the fibrous tissue, formed between both ends of distracted bone fragments, was different according to the rates of distraction (rate of $1 \mathrm{~mm} /$ day, for 30 days, Fig. 3a), (rate of $2 \mathrm{~mm} /$ day, for 15 days, Fig. 3b), (rate of $3 \mathrm{~mm} /$ day, for 10 days, Fig. 3c). The intramedullary space of the most rapidly distracted group was filled with thick fibrous tissue (Fig. 3c).

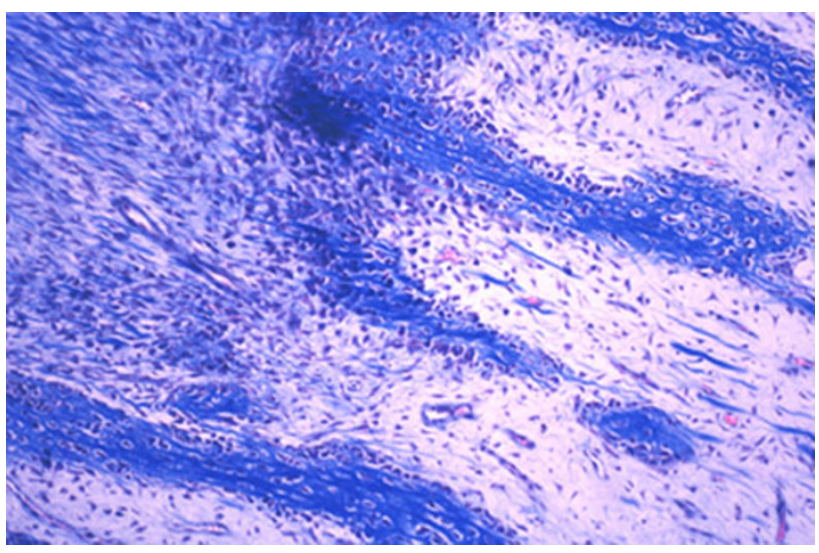

Fig. 5 Microphotograph of endochondral ossification. Bone trabeculae were formed by endochondral ossification (Masson trichrome, $\times 100$ )

Two weeks after the end of distraction, in all groups, the sections of three levels from the regenerate zone showed both intramembranous ossification (Fig. 4a, b) and endochondral ossification (Fig. 5). At the proximal and distal ends of the fibrous tissue, chondrocytes became hypertrophic, and new bone trabeculae were formed through endochondral ossification. The cartilage tissue consisted of hypertrophic chondrocytes invaded by neovessels, and mesenchymal cells, abundant fibrous tissue and new bone gradually replaced the surface of the eroded cartilage (Fig. 6, 7). The fibrous tissue showed abundant vessels and mesenchymal cells in both forms of ossification (Fig. 8a). In the process of endochondral ossification, even small amounts of cartilage bands and islands within the fibrous tissue were clearly demonstrated (Fig. 8b).

Four weeks after the end of distraction, in all groups, the sections from the regenerate showed a large amount of newly formed bone trabeculae through both intramembranous and endochondral ossification (Fig. 9). Cartilaginous remnants were clearly shown within the newly formed bone trabeculae (Fig. 10, 11), and some hypertrophic chondrocytes were also seen within the trabeculae in this phase. Avascular cartilage tissue was irregularly invaded by vessels and mesenchymal cells, and then replaced by newly formed bone. The appearance of new bone trabeculae, surrounded by vessels with abundant fibrous tissue and absorbed by numerous osteoclasts, indicated the process of bone remodeling (Fig. 11).

Morphometrical analysis showed that the proportion of cartilage tissue at level 2 was significantly larger than that at level 1 and level $3(P<0.005)$, both at 2 and 4 weeks after the end of distraction. The proportion of cartilage tissue within the regenerate was significantly decreased at 4 weeks after the end of distraction compared with that of 2 weeks after the end of distraction $(P<0.01)$ (Data not shown). 
Fig. 6-7 Vascular invasion into cartilage lacunae. Fibrous tissue, with abundant mesenchymal cells and vessels, irregularly invaded the avascular cartilage area and formed bone (Masson trichrome, $\times 100$ )

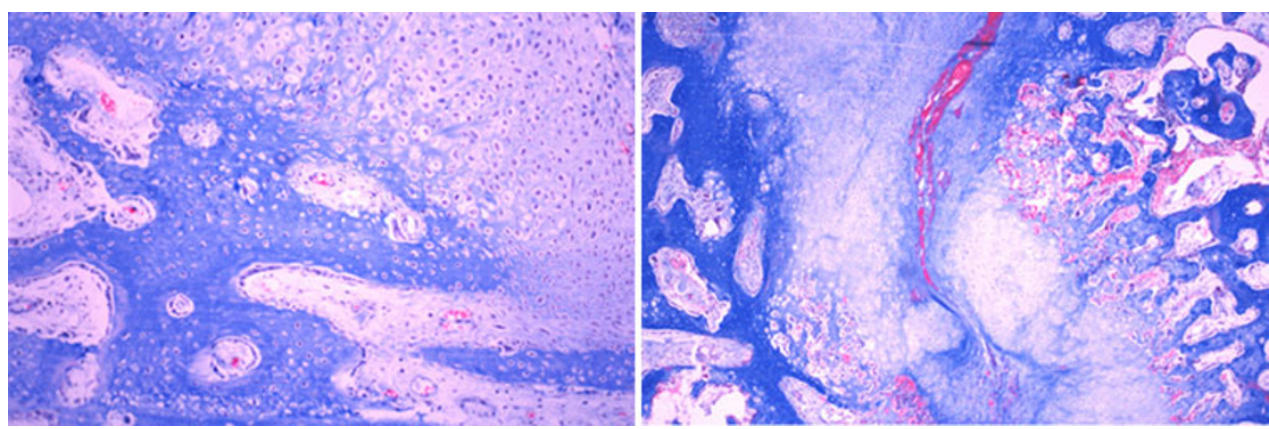

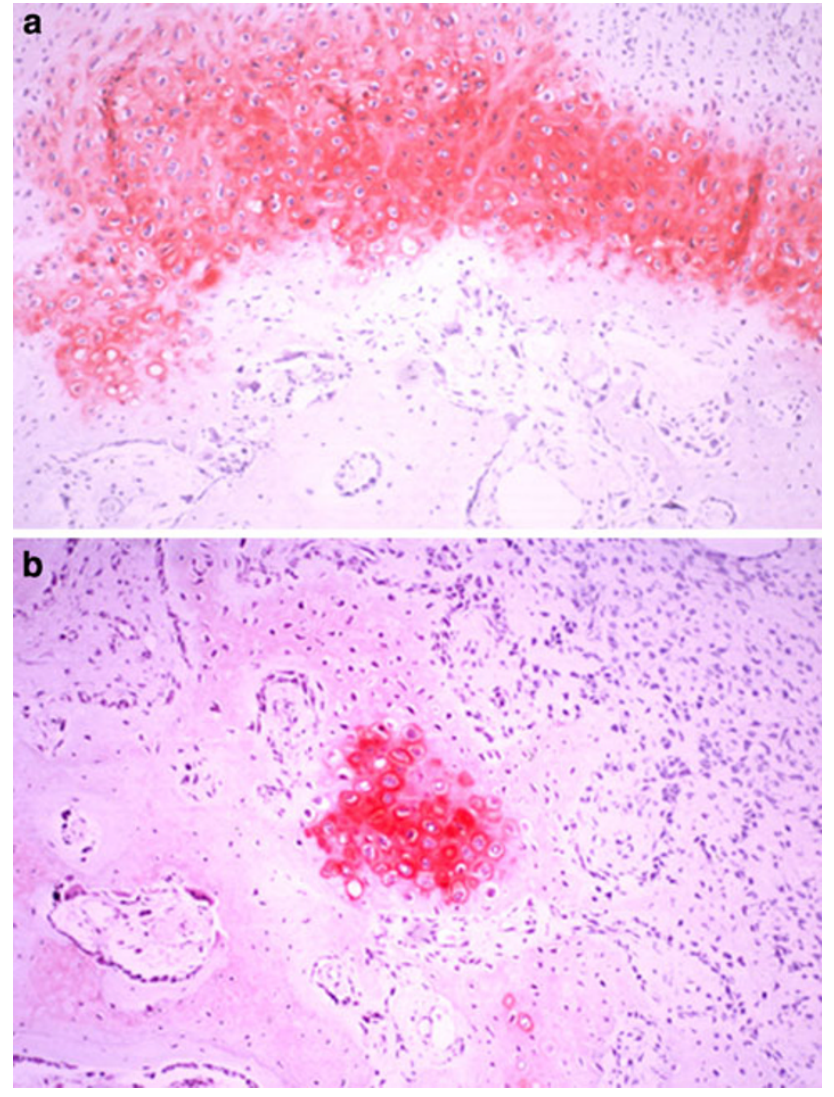

Fig. 8 Cartilage bands (a) and islands (b) within the fibrous tissue were clearly demonstrated by Safranin-O (Safranin-O, $\times 40)$

Immunohistochemical evaluation

At immunohistochemistry, we detected the location of type I and II collagen, S-100 protein, and fibronectin. Staining against type I collagen, the immunoreactive area (IR) was seen on the periphery of new bone trabeculae at all levels (Fig. 12). An IR in the fibrous tissue was seen at all levels in group 2, indicating osteogenesis. Staining against type II collagen, IR was broadly seen not only in cartilage tissue but also in cartilage remnants within the new bone trabeculae, especially in the animals in group 2 . Band-like arrangement of matrices-rich hypertrophic chondrocytes, scattered in the fibrous tissue, were also positive for

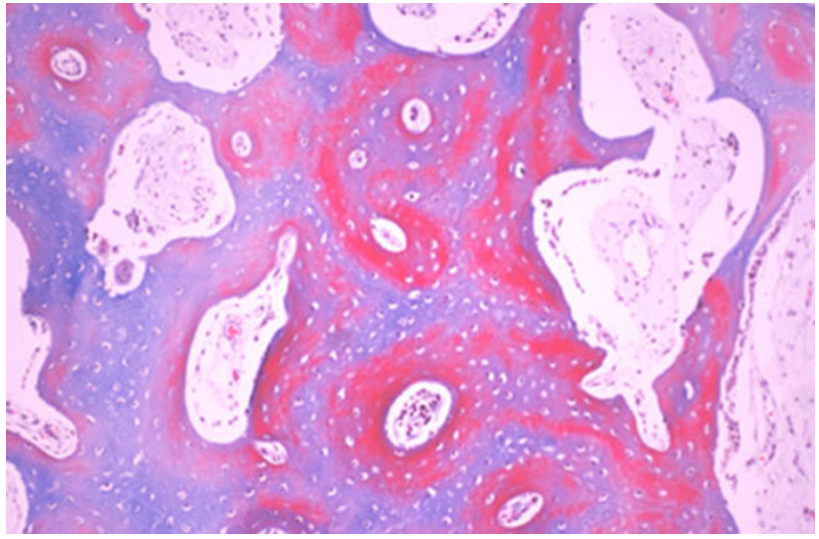

Fig. 9 Four weeks after 4 the end of distraction, all groups showed a large amount of newly formed bone trabeculae through both intramembranous and endochondral ossification (Masson trichrome, $\times 40)$

anti-type II collagen antibody (Fig. 13). The staining features against S-100 protein and fibronectin were similar, as these two proteins are both involved in endochondral bone formation. IRs against fibronectin and S-100 protein were observed in the cartilage tissue, the central region of the newly formed bone trabeculae, and some of chondrocytes within the bone trabeculae. Some cells, which were seen in the fibrous tissue in scattered form, also showed IR against fibronectin and S-100 protein, especially in the area close to the cartilage/bone transitional regions (Fig. 14).

\section{Discussion}

We evaluated the morphological features of the newly formed tissue in an experimental model of tibial lengthening in sheep. A combination of intramembranous and endochondral ossification occurs simultaneously at the site of distraction.

For logistic and practical reasons, we performed the daily lengthening in a non-fractionated manner. We are aware that quasi-continuous lengthening produces better bone formation, and that, in humans, lengthening seems to be optimal when undertaken four times a day (for example, $1 \mathrm{~mm}$ of 
Fig. 10-11 Cartilaginous remnants were clearly shown within the newly formed bone trabeculae (Masson trichrome, $\times 40)$
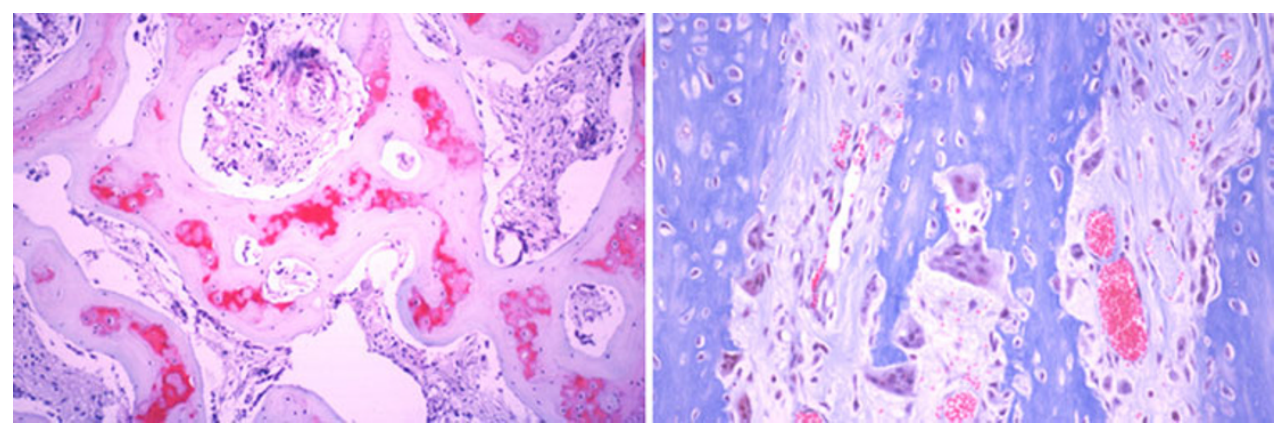

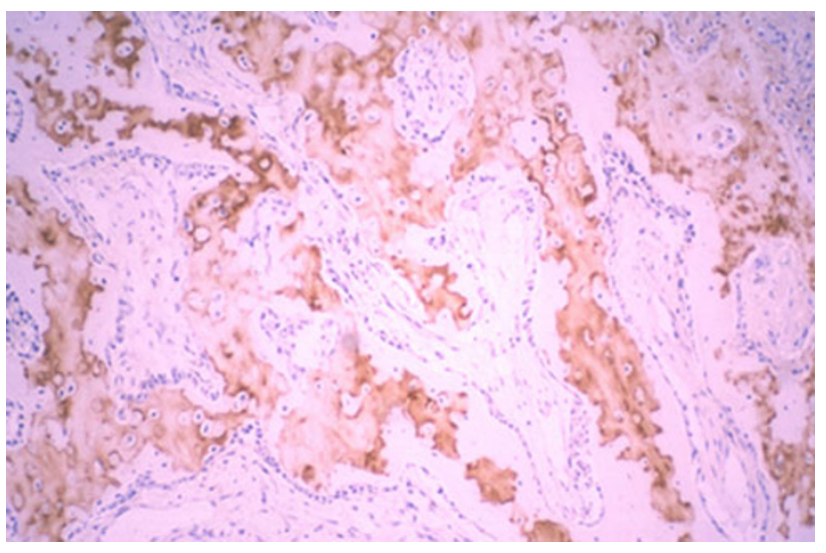

Fig. 12 Staining against type I collagen: an immunoreactive area was seen on the periphery of new bone trabeculae at all levels (anti-type I collagen antibody, $\times 40$ )

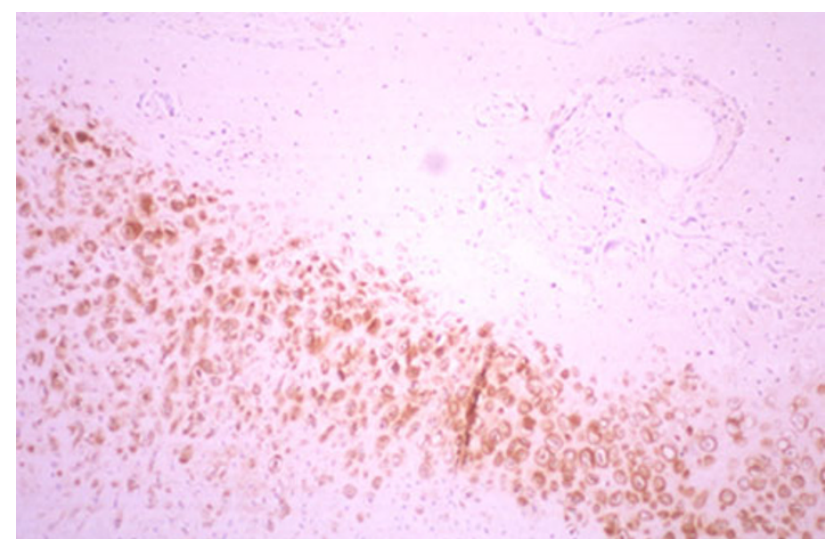

Fig. 13 Band-like arrangement of matrices-rich hypertrophic chondrocytes, scattered in the fibrous tissue, was also positive for anti-type II collagen antibody anti-type II collagen antibody, $\times 40$ )

lengthening per day should be accomplished using a 0.25 $\mathrm{mm}$ lengthening four times a day) [11-13]. However, our lengthening regimen was the same for all our animals, and the results obtained were consistent in all the sheep within the same lengthening group. Therefore, we believe that our results are scientifically valid and clinically relevant.

Concerns remain on the type of ossification occurring during callotasis. Previous reports on distraction

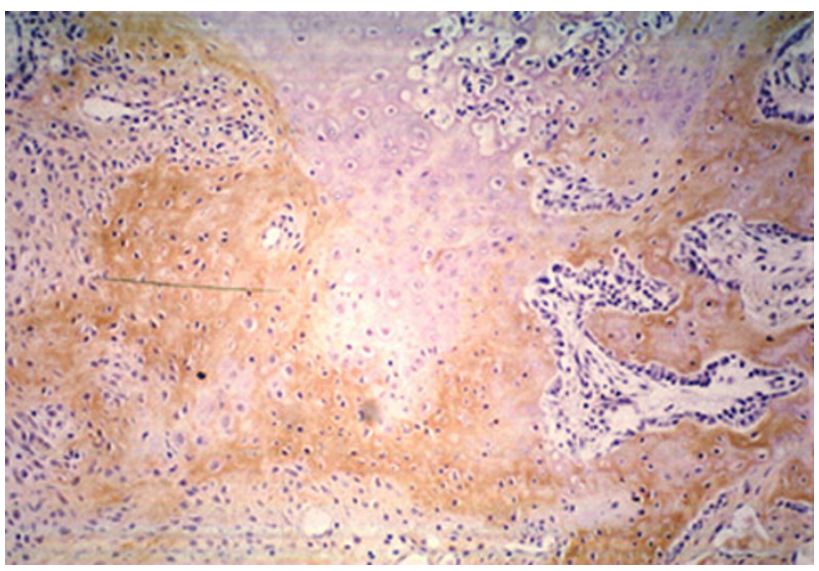

Fig. 14 Fibronectin-expressing cells, in the fibrous tissue, produced chondroid bone (anti-fibronectin antibody, $\times 40$ )

osteogenesis at low rates of distraction $(0.5-1.0 \mathrm{~mm} / \mathrm{day})$ in humans, dogs and sheep showed that the regenerate formed by intramembranous ossification [22, 23, 27-29], as also confirmed by biochemical analysis [28, 30]. However, in a rabbit model of leg lengthening, consecutive cartilage formation from the central fibrous tissue of the distraction regenerate was observed [24]. Later, a combination of intramembranous and endochondral ossification was demonstrated to occur simultaneously within the regenerate in $\operatorname{dog}$ and sheep [31-33, 44, 45]. With the "tension-stress effect" during distraction osteogenesis, Ilizarov found only intramembranous ossification and stated that islands of cartilage within the distraction callus were induced by mechanical instability of the distraction device with its resultant abnormal shear and bending forces $[22,23]$. Paley et al. [46] also described that the regenerate always formed by intramembranous ossification and that endochondral ossification had been observed only when vascular injury had occurred under unstable fixation or rapid distraction. A local disturbance of the blood supply, resulting from ruptured blood vessels caused by extensive distraction, could also account for the appearance of cartilaginous islands [47]. Thus, factors such as the stability of the distraction devices, timing and rate of distraction, and species-related difference have been considered to 
influence the relative contribution of intramembranous and endochondoral ossification [44, 48, 49]. Kusec et al. [48] reported a satisfactory and similar result in radiographical and histomorphometrical methods with the circular and unilateral fixators.

On the other hand, Fink et al. [44] denied the "tensionstress effect", showing numerous cartilage islands within all specimens in a canine model of distraction osteogenesis. In the current study, we observed moderate amount of cartilage tissue in all of specimens despite different rates for distraction. In addition to intramembranous ossification, gradual ossification at the surface of eroded cartilage was obviously seen. Some cartilage islands were divided into small ones by invading newly formed bone with abundant vessels.

Studying endochondral bone development of long bone in rabbits, intramembranous bone was formed by the inner layers of the periosteum, and vessels from the periosteum gradually invaded the hypertrophic chondrocytes region to begin formation of endochondral bone [27]. The intramembranous bone formation was always in advance of the endochondral bone formation both temporary and spatially [27]. Histomorphometrical analysis showed, however, that the proportion of cartilage tissue was significantly decreased 4 weeks after end of distraction compared with that 2 weeks after end of distraction [34].

The cascade of endochondral bone development in association with the role of fibronectin has been described. During mesenchymal cell proliferation, fibronectin is present in a cottony array. During chondrogenesis, it is associated with the pericellular zone of chondrocytes. During chondrolysis, loss of proteoglycans unmasks the fibronectin in the hypertrophic cartilage matrix. This "exposed" fibronectin may then serve as nidus for osteoprogenitor cell attachment and differentiation into osteoblast [46]. In the present study, we observed fibronectin in the cartilage tissue, the central region of the newly formed bone trabeculae, and some of the cells within the bone trabeculae. These findings also indicate that new bone trabeculae were formed through endochondral ossification in addition to intramembranous ossification. These findings may indicate the presence of "chondroid bone" [34], though transition from fibrous tissue to bone seemed not to be consecutive.

We showed vascular anastomoses between periosteal and endomedullary vessels, which penetrated the intracortical gaps. Some authors have shown that endochondral ossification remained mostly as cartilaginous collar adjacent to cortices and periosteal tissue, and much lesser amounts of cartilage could be observed as interface between the distracted fragments [48, 49]. In the present study, small variable amounts of cartilage were seen in the intramedullary gap, although intramembranous ossification was predominant at intracortical gaps, as has been described earlier. Recent experiments have shown that complete transverse osteotomies function well despite the temporary interruption of the medullary circulation [24, 45]. These findings were also demonstrated by the early restoration of the medullary artery during distraction.

An alternative explanation for the presence of chondrocyte-like cells suggests that chondroblasts and osteoblasts originate from a common pool of mesenchymal cells $[48,49]$. It is not possible to state which is more likely between the invasion of the chondrocyte lacunae by osteoblast progenitor cells and vessels in fibrous tissue and direct transformation of hypertrophic chondrocytes into osteoblasts.

In conclusion, we found that progressive bone lengthening produces both intramembranous and endochondral ossification. Additional biomechanical and clinical investigations are needed to improve our understanding of the physiology of callostasis.

Conflict of interest None.

\section{References}

1. Arriola F, Forriol F, Canadell J (2001) Histomorphometric study of growth plate subjected to different mechanical conditions (compression, tension and neutralization): an experimental study in lambs. Mechanical growth plate behavior. J Pediatr Orthop B 10(4):334-338

2. Forriol F, Goenaga I, Mora G, Vinolas J, Canadell J (1997) Measurement of bone lengthening forces; an experimental model in the lamb. Clin Biomech (Bristol, Avon) 12(1):17-21

3. Forriol F, Iglesias A, Arias M, Aquerreta D, Canadell J (1999) Relationship between radiologic morphology of the bone lengthening formation and its complications. J Pediatr Orthop B 8(4):292-298

4. Noonan KJ, Leyes M, Forriol F, Canadell J (1998) Distraction osteogenesis of the lower extremity with use of monolateral external fixation. A study of two hundred and sixty-one femora and tibiae. J Bone Joint Surg Am 80(6):793-806

5. Catagni MA, Ottaviani G, Combi A, Elhence A (2006) External circular fixation: a comparison of infection rates between wires and conical half-pins with threads outside or inside the skin. J Trauma 61(5):1186-1191

6. Pullen C, Manzotti A, Catagni MA, Guerreschi F (2003) Treatment of post-traumatic humeral diaphyseal nonunion with bone loss. J Shoulder Elbow Surg 12(5):436-441

7. Manzotti A, Rovetta L, Pullen C, Catagni MA (2003) Treatment of the late sequelae of septic arthritis of the hip. Clin Orthop Relat Res 410:203-212

8. Manzotti A, Pullen C, Guerreschi F, Catagni MA (2001) The Ilizarov method for failed knee arthrodesis following septic TKR. Knee 8(2):135-138

9. Boero S, Catagni M, Donzelli O, Facchini R, Frediani PV (1997) Congenital pseudarthrosis of the tibia associated with neurofibromatosis-1: treatment with Ilizarov's device. J Pediatr Orthop 17(5):675-684

10. Catagni MA, Guerreschi F, Holman JA, Cattaneo R (1994) Distraction osteogenesis in the treatment of stiff hypertrophic 
nonunions using the Ilizarov apparatus. Clin Orthop Relat Res 301:159-163

11. Maffulli N (1996) Callotasis lengthening: a review of some technical aspects. Bull Hosp Jt Dis 54(4):249-254

12. Maffulli N (1997) Longitudinal deficiency of the fibula. Operative treatment. J Bone Joint Surg Am 79(5):794-795

13. Maffulli N, Cheng JC, Sher A, Lam TP (1997) Dual-energy X-ray absorptiometry predicts bone formation in lower limb callotasis lengthening. Ann R Coll Surg Engl 79(4):250-256

14. Maffulli N, Cheng JC, Sher A, Ng BK, Ng E (1999) Bone mineralization at the callotasis site after completion of lengthening. Bone 25(3):333-338

15. Maffulli N, Fixsen J (1998) Complications of limb-lengthening in children who have an underlying bone disorder. J Bone Joint Surg Am 80(10):1552-1553

16. Maffulli N, Fixsen JA (1991) Fibular hypoplasia with absent lateral rays of the foot. J Bone Joint Surg Br 73(6):1002-1004

17. Lee DY, Cho TJ, Kim JA, Lee HR, Yoo WJ, Chung CY, Choi IH (2008) Mobilization of endothelial progenitor cells in fracture healing and distraction osteogenesis. Bone 42(5):932-941

18. Zheng LW, Ma L, Cheung LK (2008) Changes in blood perfusion and bone healing induced by nicotine during distraction osteogenesis. Bone 43(2):355-361

19. Haque T, Hamade F, Alam N, Kotsiopriftis M, Lauzier D, StArnaud R, Hamdy RC (2008) Characterizing the BMP pathway in a wild type mouse model of distraction osteogenesis. Bone 42(6):1144-1153

20. Abbaspour A, Takata S, Sairyo K, Katoh S, Yukata K, Yasui N (2008) Continuous local infusion of fibroblast growth factor2 enhances consolidation of the bone segment lengthened by distraction osteogenesis in rabbit experiment. Bone 42(1):98106

21. Sun Z, Rafferty KL, Egbert MA, Herring SW (2007) Masticatory mechanics of a mandibular distraction osteogenesis site: interfragmentary micromovement. Bone 41(2):188-196

22. Ilizarov GA (1989) The tension-stress effect on the genesis and growth of tissues: Part II. The influence of the rate and frequency of distraction. Clin Orthop Relat Res 239:263-285

23. Ilizarov GA (1989) The tension-stress effect on the genesis and growth of tissues. Part I. The influence of stability of fixation and soft-tissue preservation. Clin Orthop Relat Res 238:249-281

24. Kojimoto H, Yasui N, Goto T, Matsuda S, Shimomura Y (1988) Bone lengthening in rabbits by callus distraction. The role of periosteum and endosteum. J Bone Joint Surg Br 70(4):543-549

25. Peltonen J, Kahri A, Karaharju E, Alitalo I (1988) Regeneration after physeal distraction of the radius in sheep. Acta Orthop Scand 59(6):675-680

26. Ohyama M, Miyasaka Y, Sakurai M, Yokobori AT Jr, Sasaki S (1994) The mechanical behavior and morphological structure of callus in experimental callotasis. Biomed Mater Eng 4(4):273281

27. Rivas R, Shapiro F (2002) Structural stages in the development of the long bones and epiphyses: a study in the New Zealand white rabbit. J Bone Joint Surg Am 84-A(1):85-100

28. Tajana GF, Morandi M, Zembo MM (1989) The structure and development of osteogenetic repair tissue according to Ilizarov Technique in man. Characterization of extracellular matrix. Orthopedics 12(4):515-523

29. Aronson J, Harrison BH, Stewart CL, Harp JH Jr (1989) The histology of distraction osteogenesis using different external fixators. Clin Orthop Relat Res 241:106-116
30. Kallio TJ, Vauhkonen MV, Peltonen JI, Karaharju EO (1994) Early bone matrix formation during distraction. A biochemical study in sheep. Acta Orthop Scand 65(4):467-471

31. Jazrawi LM, Majeska RJ, Klein ML, Kagel E, Stromberg L, Einhorn TA (1998) Bone and cartilage formation in an experimental model of distraction osteogenesis. J Orthop Trauma 12(2):111-116

32. Karaharju EO, Aalto K, Kahri A, Lindberg LA, Kallio T, Karaharju-Suvanto T, Vauhkonen M, Peltonen J (1993) Distraction bone healing. Clin Orthop Relat Res 297:38-43

33. Peltonen JI, Kahri AI, Lindberg LA, Heikkila PS, Karaharju EO, Aalto KA (1992) Bone formation after distraction osteotomy of the radius in sheep. Acta Orthop Scand 63(6):599-603

34. Yasui N, Sato M, Ochi T, Kimura T, Kawahata H, Kitamura Y, Nomura S (1997) Three modes of ossification during distraction osteogenesis in the rat. J Bone Joint Surg Br 79(5):824-830

35. Maffulli N, Fixsen JA (1995) Muscular strength after callotasis limb lengthening. J Pediatr Orthop 15(2):212-216

36. Maffulli N, Fixsen JA (1996) Management of forme fruste fibular hemimelia. J Pediatr Orthop B 5(1):17-19

37. Maffulli N, Hughes T, Fixsen JA (1992) Ultrasonographic monitoring of limb lengthening. J Bone Joint Surg Br 74(1):130 132

38. Maffulli N, Lombari C, Matarazzo L, Nele U, Pagnotta G, Fixsen JA (1996) A review of 240 patients undergoing distraction osteogenesis for congenital post-traumatic or postinfective lower limb length discrepancy. J Am Coll Surg 182(5):394-402

39. Maffulli N, Nele U, Matarazzo L (2001) Changes in knee motion following femoral and tibial lengthening using the Ilizarov apparatus: a cohort study. J Orthop Sci 6(4):333-338

40. Maffulli N, Pattinson RC, Fixsen JA (1993) Lengthening of congenital limb length discrepancy using callotasis: early experience of the Hospital for Sick Children. Ann R Coll Surg Engl 75(2): $105-110$

41. Stokes IA, Clark KC, Farnum CE, Aronsson DD (2007) Alterations in the growth plate associated with growth modulation by sustained compression or distraction. Bone 41(2):197-205

42. Reinhold HS, Hopewell JW, van Rijsoort A (1983) A revision of the Spalteholz method for visualizing blood vessels. Int $\mathrm{J}$ Microcirc Clin Exp 2(1):47-52

43. Steinke H, Wolff W (2001) A modified Spalteholz technique with preservation of the histology. Ann Anat 183(1):91-95

44. Fink B, Pollnau C, Vogel M, Skripitz R, Enderle A (2003) Histomorphometry of distraction osteogenesis during experimental tibial lengthening. J Orthop Trauma 17(2):113-118

45. Delloye C, Delefortrie G, Coutelier L, Vincent A (1990) Bone regenerate formation in cortical bone during distraction lengthening. An experimental study. Clin Orthop Relat Res 250:34-42

46. Paley D, Fleming B, Catagni M, Kristiansen T, Pope M (1990) Mechanical evaluation of external fixators used in limb lengthening. Clin Orthop Relat Res 250:50-57

47. Lascombes P, Membre H, Prevot J, Barrat E (1991) Histomorphometry of bone regenerate in limb lenghthening by the Ilizarov's technique. Rev Chir Orthop Reparatrice Appar Mot 77(3):141-150

48. Kusec V, Jelic M, Borovecki F, Kos J, Vukicevic S, Korzinek K (2003) Distraction osteogenesis by Ilizarov and unilateral external fixators in a canine model. Int Orthop 27(1):47-52

49. Li G, Simpson AH, Triffitt JT (1999) The role of chondrocytes in intramembranous and endochondral ossification during distraction osteogenesis in the rabbit. Calcif Tissue Int 64(4):310-317 